Marie Laure Djelic and Frank den Hond*

\title{
Introduction: multiplicity and plurality in the world of standards
}

\author{
Symposium on multiplicity and plurality in the world \\ of standards
}

\begin{abstract}
Globalization is often described as a chaotic process which signals the end of national institutions' ability to regulate markets. However, a closer look reveals a new world of standards and regulations, often with a transnational scope and reach. Contemporary rule making and rule monitoring increasingly take place in the context of transnational arenas that bring around the table many different types of actors, all of whom have or feel to have a "stake" in the regulatory project at hand, yet often for quite diverse reasons and with varying interests. While standardization would seem to suggest regularity, rationalization, and a reduction of diversity if not the advance of homogeneity and convergence, we can easily document a surprising multiplicity and plurality in our transnational world of standards. In most industries, fields and arenas, we find multiple standards and standard setting coalitions. Even so, scholars have only barely started to explore this multiplicity and plurality. Building upon what we know on technical standards, this Symposium describes and explains important patterns in the world of transnational standard-setting, revealing the nature of this plurality and the ways in which it impacts upon and is impacted by different groups of actors involved.
\end{abstract}

*Corresponding author: Frank den Hond, Hanken School of Economics, Helsinki, Finland; and VU University, Amsterdam, The Netherlands, e-mail: frank.denhond@hanken.fi

Marie Laure Djelic: ESSEC Business School - Management Department, Cergy-Pontoise, France

\section{Introduction: transnational re-ordering}

The image of contemporary globalization as a juggernaut, as an incontrollable force generating a runaway world, ${ }^{1}$ putting society at permanent risk, ${ }^{2}$ has an

1 Giddens (2000).

2 Beck (1992). 
unmistakable allure. In this image of modernity run wild, globalization overwhelms traditional (and often national) boundaries, bonds, rules and institutions, as well as their capacity to generate order. Reality, however, is less dramatic. Globalization is not about the disappearance of rules and order. In fact, it could aptly be described as a "golden era of regulation." ${ }^{3}$ It comes together with an increasing density of regulatory and governance activities of all kinds and with a consequential process of re-ordering. ${ }^{4}$

The dynamics of this consequential process of re-ordering and its transnational scope and reach have generated a fair amount of scholarly attention. ${ }^{5}$ Arguably, the landscape that emerges contrasts quite significantly with traditional, nationally bound rule-of-law systems. In the twentieth-century Westphalian world, nation states had a quasi-monopoly over rule making and rule monitoring, which they could partially delegate in certain circumstances - but always keeping an authority of last resort. In contrast, contemporary rule making and rule monitoring increasingly take place in the context of transnational arenas that bring around the table many different types of actors, all of whom have or feel to have a "stake" in the regulatory project at hand, yet often for quite diverse reasons and with varying interests. The consequence is a privatization of some sort of governance capacity and authority, often without a clear ownership of the project. ${ }^{6}$ States remain involved, but in different ways. In certain circumstances, they may themselves become subject to transnational regulatory activities, hence turning into "regulated regulators."

Such transnational arenas of private authority get structured around particular regulatory projects and agendas. They bring together a number of stakeholders often presented as a "coalition." In general, we find around the table private corporations, non-governmental organizations of different kinds, expert communities, private international organizations (such as ISO) and/or quasipublic international organizations (such as the OECD or the IMF). There is variability, however, across regulatory project arenas as to the particular make-up (number and type) of stakeholders that are involved as well as to the power balance among them. ${ }^{8}$ Their important task is to codify, frame and standardize

3 Levi-Faur and Jordana (2005: p. 6).

4 Vogel (1996); Braithwaite and Drahos (2000); Djelic and Sahlin-Andersson (2006).

5 e.g., Djelic and Sahlin-Andersson (2006); Graz and Nölke (2008); Mattli and Woods (2009); Büthe (2010); Zürn (2012).

6 Higgot, Underhill and Bieler (2000); Hall and Biersteker (2002); Bartley (2007); Graz and Nölke (2008); Büthe and Mattli (2011).

7 Jacobsson (2006); Shaffer (2013).

8 Djelic and Sahlin-Andersson (2006). 
practices, in particular by issuing soft law. ${ }^{9}$ Transnational soft law takes the form of rules, white papers, norms, guidelines or standards. ${ }^{10} \mathrm{~A}$ common characteristic of all variants of soft law is that they lack "the possibility of legal sanctions ... and hence are not legally binding." ${ }^{11}$ In a deep sense, soft law is voluntary and its adoption will be contingent upon what we might call a new architecture of persuasion. Hence, the spread of soft law comes together with an explosion of associated mechanisms and processes that are activated on the one hand to "persuade," "convince," or "softly coerce" their targets to comply, and on the other hand to monitor the adoption and implementation of soft rules, norms or standards. ${ }^{12}$ Another characteristic of soft law instruments is that they generally tend to be somewhat flexible, leaving space for interpretation and adjustment even after they have been enacted and adopted. ${ }^{33}$ This inherent flexibility creates significant opportunities for localized adaptation or "translation" 14 but also for shirking and avoiding, for what John Meyer calls “decoupling” and Nils Brunsson “organized hypocrisy." 15

\section{The "law of rules" and transnational standardization}

Standards are important elements of our contemporary transnational soft-governance architecture. ${ }^{16}$ Beyond the apparent simplicity of the word, discussions around the definition and nature of "standards" are still intense. Typically, the term "standard" is used to identify highly formalized sets of rules with a high degree of specificity. This opposes them, on the one hand, to broader and more general principles and, on the other hand, to more informal guidelines or best practices. ${ }^{17}$ Still, the lines separating these different types of non-legally binding rules can be rather fuzzy and this translates into quite different definitions. On the one hand, the International Organization for Standardization (ISO) proposes a rather narrow definition of a standard as:

9 Kirton and Trebilcock (2004); Mörth (2004); Djelic (2011); Shaffer (2013).

10 Brunsson and Jacobsson (2000).

11 Mörth (2004: p. 1)

12 Monitoring may be extended to include systems for certification, rating or ranking. Boli (2006); Davis et al. (2012).

13 Kirton and Trebilcock (2004); Djelic and Sahlin-Andersson (2006).

14 Sahlin and Wedlin (2008).

15 Meyer and Rowan (1977); Brunsson (1989).

16 Egan (2001); den Hond et al. (2007).

17 Ahrne and Brunsson (2006: p. 82); Braithwaite and Drahos (2000: p. 20). 
a document, established by consensus and approved by a recognized body, that provides, for common and repeated use, rules, guidelines or characteristics for activities or their results, aimed at the achievement of the optimum degree of order in a given context..$^{18}$

On the other hand, calls have been made for a broader and more encompassing understanding of standards as "pieces of general advice offered to a large number of potential adopters." ${ }^{19}$ Timmermans and Epstein take an altogether different approach by focusing on standard setting rather than on standards. ${ }^{20}$ We agree that this is probably the most fruitful approach. Thus, standard setting is:

a process of constructing and implementing agreed-upon rules, usually backed by some external body, with the aim of creating uniformity across time and space between different localized activities. ${ }^{21}$

Scholarly research has zoomed in recent years on the dynamics of transnational standardization and standard setting. ${ }^{22}$ As a result of this collective scholarly exploration, we now understand better what transnational standards are and how they contribute to the regulation and governance of behaviors, organizations and even institutions. We have come to recognize the power of standards (and of soft law in general), not only as mechanisms of governance, but in fact as potent "technologies of government" 23 that appear to work despite an absence of coercive bite and of democratic authority and legitimacy. We have managed to get a sense of who are the various actors involved in processes of transnational standard setting and monitoring. We also have a much better understanding of the nature, complexities and dynamics of the standard setting process. We are increasingly able to map the ways in which very different actors manage to work together, overcoming differences and disagreements and progressively moving toward the formulation and formalization of shared understandings. ${ }^{24}$

18 ISO/IEC 2004. This definition has itself become a "standard" for the definition of standards. It has been appropriated word for word by most national or transnational normalizing or standardizing organizations.

19 Brunsson and Jacobsson (2000: p. 2).

20 Timmermans and Epstein (2010).

21 Djelic and Quack (2012: p. 169).

22 Tamm-Hallström and Boström (2010); Timmermans and Epstein (2010); Botzem and Dobusch (2012); Brunsson, Rasche and Seidl (2012).

23 Rose and Miller (1992).

24 Tamm Hallström (2004); Djelic and Quack (2010); Tamm Hallström and Boström (2010); Timmermans and Epstein (2010); Dobusch and Quack (2012). 


\section{Multiplicity and plurality of standards: a paradox?}

At the same time, though, our collective exploration has also uncovered an unexpected and very paradoxical evolution that generates a whole set of new questions. While standardization would seem to suggest regularity, rationalization, and a reduction of diversity if not the advance of homogeneity and convergence, we can easily document a surprising multiplicity and plurality in our transnational world of standards. In most industries, fields and arenas, we find multiple standards and standard setting coalitions. It has been said before: the world is "full of standards" but it is far from being "fully standardized." 25 In some regulatory fields, according to Reinecke and her colleagues, we may even have "standards markets," which places transnational standardization coalitions in a predicament:

While claiming that they [i.e., transnational standardization coalitions] are pursuing shared, overarching objectives, at the same time, they are promoting their own respective standards. ${ }^{26}$

However, we have only barely started to explore the multiplicity and plurality in the world of standards. Building upon what we know on technical standards, we can anticipate a number of different possible scenarios. ${ }^{27}$ In some situations, transnational standards and standard setting coalitions could enter in fierce competition with each other. In other cases, they would appear instead to be complementary. In principle, they could also simply co-exist in the medium and long-term - structuring different standard "clubs" or "communities" with limited interface. They could also come to interact and create, over time, mechanisms of coordination, if not cooperation, with at least three different possible outcomes. Firstly, one of the standards could simply take over. Secondly, we could see the emergence of a negotiated hybrid. Or, finally, we could even anticipate the structuration of an additional layer of standardization and the emergence of a "meta-standard," for example, in the form of a standard of standardization. ${ }^{28}$

When we framed the call for this Symposium, we departed from precisely this conviction that the exploration of the surprising multiplicity and plurality

25 Timmermans and Epstein (2010).

26 Reinecke, Manning and von Hagen (2012: p. 789).

27 E.g. Hawkins, Mansell and Skea (1995); Schmidt and Werle (1998); von Burg (2001); Funk (2002); Russell (2005).

28 Endres (2010). 
of standards was long overdue. This, we propose, is an important frontier for the contemporary dense scholarship on transnational standards and standard setting. As we go on exploring the variable complexities associated with this multiplicity and plurality, we should also naturally reflect upon the particular complexities generated by appropriation through a variety of tools and measurement devices used for compliance, as well as by the great diversity of contexts and contextual conditions in which appropriation takes place.

\section{This symposium}

This Symposium attempts to move in that direction by starting to explore the Multiplicity and Plurality in the World of Standards. Apart from this introductory essay, it comprises four original articles that each focus on different regulatory arenas. All four articles start from a curiosity for the striking density of standards and standardization initiatives in contemporary governance. The common thread is to assess, in distinct regulatory arenas, the nature of this plurality and the ways in which it impacts upon and is impacted by different groups of actors involved. Graz and Hauert focus on the service sector and its transnational regulation. Thiemann looks at the regulatory arena for accounting standards. Turcotte, Reinecke and den Hond explore social and environmental standards plurality in and across three different regulatory arenas: forestry, coffee and textile. Finally, McCaffrey and Kurland explore the case of the "buy-local" standardization arena in the US - this is the only paper in the Symposium that focuses on standards multiplicity within a single country.

These four papers simply "emerged" from the classical peer review process associated with the production of this Symposium. There is hence no real "logic" to the juxtaposition of the different regulatory arenas they discuss. Nor could they be said to explore a "representative sample" of contemporary regulatory arenas. Nevertheless, and collectively, they cover significant regulatory ground and provide a good starting point, we believe, for the type of exploratory project we had in mind.

The first article by Jean-Christophe Graz and Christophe Hauert explores how in the American, transnational (ISO), and European institutional environments for standard stetting, service standards are being developed, and how, vice-versa, the process may affect different institutional environments. It starts from the premise that in many ways, the possibility to develop global markets depends on the standardization of products and services. However, standards often originate from specific institutional environments with distinct traditions. 
In the case of service standards, the intangibility and embeddedness of services in the producer-customer relationship poses severe challenges: whether services can be standardized at all, and if so, what approach should be taken. Graz and Hauert seek to understand how the different ISO, European and American traditions of standard setting may play out in the case of service standards. Assessing which actors may assume authority over standard setting, what it is that is being standardized, and the space in which the standards are to be implemented and recognized as legitimate, they argue for a more nuanced understanding of the emerging transnational hybrid authority in service standards. They suggest that, behind an apparently stable and institutionalized plurality of standard setting arenas (US, ISO, Europe), there are in fact some deep and highly structuring parallel evolutions - that could bring those arenas and their initiatives closer to each other than we would expect at first sight. For example, the key and most powerful actors in the standard setting process "are the same," they tell us, across those three arenas: "large firms dominate technical committees" and "civil society remains largely underrepresented." On the other hand, the apparent divisive debates between champions of "horizontal" standardization (mostly US) and those who are fighting for "vertical" standardization processes (mostly Europe) could be strongly mitigated if not overcome through the emergence of a third way: the "development of a customer satisfaction index" as the first step towards standardization from a customer-based perspective.

The second article, by Matthias Thiemann, looks at international accounting standards with a particular focus on the IFRS standard for off-balance sheet financing (SIC 12). The approach is here again institutional and the question of plurality emerges through the exploration of the necessary process of national appropriation and interpretation in three countries (France, Germany and the Netherlands) of what turns out to be a rather fluid transnational standard. An interesting argument, in this article, is that the process of standardization should be understood and explored in a broad manner: well beyond the negotiation and construction of formal rules and norms, well beyond the generation of a "legitimate document" to paraphrase ISO and its proposed definition of standardization..$^{29}$ As suggested above, standard setting is also - and very much so - about the process of "implementing agreed-upon rules." 30 The article by Thiemann explores precisely the striking plurality that stems from the encounter between a single international standard and complex domestic institutional settings and governance architectures. And it brings to the fore an interesting paradox. The transnational standard, in fact, had more chances

29 ISO/IEC (2004).

30 Djelic and Quack (2012: p. 169). 
of being diffused and appropriated if this diffusion did not come together with the attempt to copy the governance architecture of the international standard setter (IASB). In other words, diffusion and appropriation of the same standards (and hence standard convergence) was more likely if it happened through and not against a plurality of highly native and embedded domestic institutions and governance architectures.

In the third article Marie-France Turcotte, Juliane Reinecke and Frank den Hond examine the trajectories of social and environmental standard setting in the coffee, forestry and textile sectors. Multiplicity, here, is almost like a variable: it can be less - a "quasi-duopoly" in the forestry sector - or more - "continued fragmentation" in the textile sector - or something in between, as found in the coffee sector. In each of these sectors, initial standard setting activities were propagated by different types of actors; initial standard setting provoked subsequent standard setting; the resulting multiplication of standards was a reason for attempting rationalization, harmonization, and convergence, yet with mixed results; and today, some two decades after the private regulation of social and environmental issues really took off, in each of these sectors there are multiple (coalitions of) standards. As each of these sectors went through a unique trajectory, Turcotte et al. try to explain the variety in the trajectories and outcomes. They suggest that the economic, idealist or political-institutional perspectives cannot on their own explain the trajectories and outcome. Rather, they suggest that these perspectives describe different action logics that are available to participants in the standard setting process, and that standard setting has an idiosyncratic dynamic that is fed by sector specific conditions, by intra-sector relationships, and by observing and learning from the experiences in standard setting in other sectors.

Finally, Sara Jane McCaffrey and Nancy Kurland examine the US "buy local" movement. The problem this movement faces is that, having established market niches with the help of three national NGOs that operate as second-party certifiers, large retailers have started to "hijack" their markets for local products. Apart from the risk of losing market shares, there is also the risk that the general category of "buy local" labels loses credibility as these national retailers introduce their own private labels that typically compromise the criteria that the original NGO labels seek to advance. These issues provoked considerable debate among the leaders of the "buy local" movement. While some leaders worked to create clear, transparent and harmonized criteria for what it means to be "local," many others resisted such efforts, at the risk of exposing their markets to ongoing assaults by large national retailers. Such behavior seems to be counter-intuitive and difficult to appreciate in the light of current understandings of the market dynamics around ethical labels, as McCaffrey and Kurland suggest. But perhaps it is not. Their interviews revealed various "pragmatic, philosophical and strategic" 
reasons why "buy local" leaders would resist harmonization of standards. While this study does not provide a final answer to questions around the persistence of multiple standards and standard setting kernels, it does question some received insights and thereby offers inroads for further studies of multiplicity of standards.

This Symposium set itself the modest ambition to identify and frame some of the key questions related to the striking paradox of standards multiplicity. The four different articles in this Symposium explore this paradox in different regulatory arenas and institutional contexts. This is only a beginning, though: we hope that by starting this conversation, we can stimulate further empirical explorations of a diversity of regulatory arenas, which in turn will generate ground for theoretical contributions.

\section{References}

Ahrne, Göran, and Nils Brunsson. 2006. “Organizing the World.” In Transnational Governance: Institutional Dynamics of Regulation, edited by Marie Laure Djelic and Kerstin SahlinAndersson. Cambridge: Cambridge University Press.

Bartley, Tim. 2007. "Institutional Emergence in an Era of Globalization: The Rise of Transnational Private Regulation of Labor and Environmental Conditions." American Journal of Sociology 113 (2): 297-351.

Beck, Ulrich. 1992. Risk Society. Towards a New Modernity. London: Sage.

Boli, John. 2006. "The Rationalization of Virtue and Virtuosity in World Society." In Transnational Governance, edited by Marie Laure Djelic and Kerstin Sahlin-Andersson. Cambridge: Cambridge University Press.

Botzem, Sebastian, and Leonhard Dobusch. 2012. "Standardization Cycles: A Process Perspective on the Formation and Diffusion of Transnational Standards." Organization Studies 33 (5-6): 737-762.

Braithwaite, John, and Peter Drahos. 2000. Global Business Regulation. Cambridge: Cambridge University Press.

Brunsson, Nils. 1989. The Organization of Hypocrisy: Talk, Decisions and Actions in Organizations. New York: Wiley.

Brunsson, Nils, and Bengt Jacobsson. 2000. A World of Standards. Oxford and New York: Oxford University Press.

Brunsson, Nils, Andreas Rasche, and David Seidl. 2012. The Dynamics of Standardization: Three Perspectives on Standards in Organization Studies. Organization Studies 33 (5-6): 613-32.

Büthe, Tim. 2010. "Private Regulation in the Global Economy: A (P)Review.” Business and Politics 12 (3): 1-38.

Büthe, Tim, and Walter Mattli. 2011. The New Global Rulers: The Privatization of Regulation in the World Economy. Princeton: Princeton University Press.

Davis, Kevin, Angelina Fisher, Benedict Kingsbury, and Sally Engle Merry, eds. 2012. Governance by Indicators: Global Power through Classification and Rankings. Oxford and New York: Oxford University Press. 
den Hond, Frank, Frank G. A. de Bakker, and Peter Neergaard. 2007. "Introduction to Managing Corporate Social Responsibility in Action." In Managing Corporate Social Responsibility in Action: Talking, Doing and Measuring, edited by Frank den Hond, Frank G. A. de Bakker and Peter Neergaard. Aldershot: Ashgate.

Djelic, Marie Laure. 2011. "From the Rule of Law to the Law of Rules: The Dynamics of Transnational Governance and their Local Impact." International Studies of Management and Organization 41 (1): 35-61.

Djelic, Marie Laure, and Sigrid Quack, eds. 2010. Transnational Communities. Cambridge: Cambridge University Press.

Djelic, Marie Laure, and Sigrid Quack. 2012. "Transnational Governance through Standard Setting: The Role of Transnational Communities." In Capitalisms and Capitalism in the 21st Century, edited by Glenn Morgan and Richard Whitley. Oxford: Oxford University Press.

Djelic, Marie Laure, and Kirsten Sahlin-Andersson, eds. 2006. Transnational Governance. Cambridge: Cambridge University Press.

Dobusch, Leonhard, and Sigrid Quack. 2012. “Framing standards, mobilizing users: Copyright versus fair use in transnational regulation." Review of International Political Economy 20 (1): 52-88.

Egan, Michelle. 2001. Constructing a European Market. Standards, Regulation, and Governance. Oxford and New York: Oxford University Press.

Endres, Jody M. 2010. "Clearing the Air: The Meta-Standard Approach to Ensuring Biofuels Environmental and Social Sustainability." Virginia Environmental Law Journal 28 (73): 73-120.

Funk, Jeffrey L. 2002. Global Competition Between and Within Standards: The Case of Mobile Phones. London: Palgrave.

Giddens, Anthony. 2000. Runaway World: How Globalization is Reshaping Our Lives. London: Routledge.

Graz, Jean-Christophe, and Andreas Nölke, eds. 2008. Transnational Private Governance and its Limits. Milton Park: Routledge.

Hall, Rodney B., and Thomas J. Biersteker, eds. 2002. The Emergence of Private Authority in Global Governance. Cambridge: Cambridge University Press.

Hawkins, Richard, Robin Mansell, and Jim Skea, eds. 1995. Standards, Innovation, and Competitiveness: Politics and Economics of Standards in Natural and Technical Environments. Cheltenham: Edward Elgar.

Higgott, Richard, Geoffrey R. D. Underhill, and Andreas Bieler. 2000. Non-State Actors and Authority in the Global System. London: Routledge.

ISO/IEC. 2004. "ISO/IEC Guide 2:2004: Standardization and related activities General vocabulary.” Available through http://www.iso.org/iso/catalogue_detail. htm?csnumber=39976, accessed November 2013.

Jacobsson, Bengt. 2006. “Regulated Regulators. Global Trends of State Transformation.” In Transnational Governance, edited by Marie Laure Djelic and Kerstin Sahlin-Andersson, pp. 205-24. Cambridge: Cambridge University Press.

Kirton, John J., and Michael J. Trebilcock. 2004. Hard Choices, Soft Law: Voluntary Standards in Global Trade, Environment and Social Governance. Aldershot: Ashgate.

Levi-Faur, David, and Jacint Jordana. 2005. "Globalizing Regulatory Capitalism." The Annals of the American Academy of Political and Social Science 598 (1): 6-9.

Mattli, Walter, and Ngaire Woods, eds. 2009. The Politics of Global Regulation. Princeton: Princeton University Press. 
Meyer, John, and Brian Rowan. 1977. "Institutionalized Organizations: Formal Structure as Myth and Ceremony." American Journal of Sociology 83 (2): 340-63.

Mörth, Ulrika, ed. 2004. Soft Law in Governance and Regulation: An Interdisciplinary Analysis. Cheltenham: Edward Elgar.

Reinecke, Juliane, Stephan Manning, and Olivier von Hagen. 2012. "The Emergence of a Standards Market: Multiplicity of Sustainability Standards in the Global Coffee Industry." Organization Studies 33 (5-6): 789-812.

Rose, Niklas, and Peter Miller. 1992. "Political Power beyond the State: Problematics of Government.” British Journal of Sociology 43 (2): 173-205.

Russell, Andrew L. 2005. "Standardization in History: A Review Essay with an Eye to the Future.” In The Standards Edge: Future Generations, edited by Sherrie Bolin. Ann Arbor: Sheridan Books.

Sahlin, Kerstin, and Linda Wedlin. 2008. "Circulating Ideas: Imitation, Translation and Editing." In Handbook of Organizational Institutionalism, edited by Royston Greenwood, Christine Olivier, Roy Suddaby and Kerstin Sahlin. London: Sage.

Shaffer, Gregory, ed. 2013. Transnational Legal Ordering and State Change. Cambridge: Cambridge University Press.

Schmidt, Susanne K., and Raymund Werle. 1998. Coordinating Technology: Studies in the International Standardization of Telecommunications. Cambridge, MA: MIT Press.

Tamm-Hallström, Kristina. 2004. Organizing International Standardization. ISO and the IASC in Quest of Authority. Cheltenham: Edward Elgar.

Tamm-Hallström, Kristina, and Magnus Boström. 2010 Transnational Multi-Stakeholder Standardization: Organizing Fragile Non-State Authority. Cheltenham: Edward Elgar.

Timmermans, Stefan, and Steven Epstein. 2010. "A World of Standards but not a Standard World: Toward a Sociology of Standards and Standardization." Annual Review of Sociology 36 (1): 69-89.

Vogel, Steven K. 1996. Freer Markets, More Rules: Regulatory Reform in Advanced Industrial Countries. Ithaca: Cornell University Press.

von Burg, Urs. 2001. The Triumph of Ethernet: Technological Communities and the Battle for the LAN Standard. Stanford: Stanford University Press.

Zürn, Michael. 2012. "Global Governance as Multi-level Governance.” In The Oxford Handbook of Governance, edited by David Levi-Faur. Oxford and New York: Oxford University Press. 